Digitais do gênero feminino nas cerâmicas contemporâneas e possivelmente nas peças arqueológicas no Amazonas - Brasil

\begin{tabular}{c|c|c}
\hline ISSN 2525-4812 (versão online) & Recebido em: 19/6/2019 & Revista Terceira \\
ISSN 2238-7641 (versão impressa) \\
$\begin{array}{c}\text { http://www.revistaterceiramargem.com/ } \\
\text { index.php/terceiramargem/index }\end{array}$ & $\begin{array}{c}\text { Aprovado em: 30/2/2020 } \\
\text { Período de publicação: jul/dez, 2020 }\end{array}$ & $\begin{array}{c}\text { Margem Amazônia } \\
(\mathrm{v} .6 \cdot \mathrm{n} .15 \cdot \mathrm{Jul} / \mathrm{Dez} 2020)\end{array}$ \\
\hline
\end{tabular}

Como citar o artigo:

SILVA, C. A; BRITO, A. K. R; FRAXE, T. J. P. Digitais do gênero feminino nas cerâmicas contemporâneas e possivelmente nas peças arqueológicas no Amazonas - Brasil Revista Terceira Margem Amazônia, v. 6, n.15, p. 166-181, 2020. Doi: http://dx.doi.org/10.36882/2525-4812.2020v6i15p166-181.

\title{
DIGITAIS DO GÊNERO FEMININO NAS CERÂMICAS CONTEMPORÂNEAS E POSSIVELMENTE NAS PEÇAS ARQUEOLÓGICAS NO AMAZONAS-BRASIL
}

\author{
Carlos Augusto da Silva ${ }^{1}$ \\ Ane Karoline Rosas Brito ${ }^{2}$ \\ Therezinha de Jesus Pinto Fraxe ${ }^{3}$
}

Resumo: O objetivo do artigo foi perceber como ocorria o uso de saberes ancestrais nas cerâmicas contemporâneas e na perspectiva da arqueologia hodierna. Para conceber tal percepção, realizou-se visita à comunidade Cai N'água, em Manaquiri-Amazonas, para observar como as oleiras as utilizaram para a confecção de recipiente cerâmico e as funções sociais das cerâmicas entre essas mulheres, além de como elas produziam os recipientes e lhes davam uso no cotidiano. Ao fim, descobriu-se que as oleiras tinham uma verdadeira vitrina em que os modelos arquitetônicos eram com base na fauna e estavam de acordo com o gênero que usaria os recipientes, no caso dos alguidares. Finalmente, chegou-se à conclusão de que as oleiras praticavam uma técnica de modelagem cerâmica milenar cuja digital ainda está presente nos recipientes contemporâneas e possivelmente na vida pretérita.

Palavras-chave: Cerâmica contemporânea; cerâmicas arqueológicas; cultura material e imaterial; cerâmica no Amazonas.

Abstract: The objective of this article was to understand how the use of ancestral knowledge in contemporary ceramics and in the perspective of contemporary archeology occurred. In order to conceive this perception, a visit to the Cai N'água community in Manaquiri-Amazonas was carried out to observe how the pots were used by women to make a ceramic container and the social functions of ceramics among them, as well as how they produced the containers and gave them daily use. At the end, it was discovered that the pottery had a veritable showcase in which the architectural models were based on

\footnotetext{
${ }^{1}$ Doutorado em Sociedade e Cultura na Amazônia pela UFAM - 2016. Professor colaborador do PPGCASA, Bolsista do TEC - Tribunal de Contas do Amazonas - casilva1956@ gmail.com

${ }^{2}$ Graduada em Turismo pela Faculdade Metropolitana - Manaus-AM - 2014, com Especialização pelo IFAM-Zona Leste de Manaus - 2018 - anerosas86@ gmail.com

${ }^{3}$ Professora Titular da Universidade Federal do Amazonas (FCA-PPGCASA) - ecafraxe@uol.com.br
} 
Digitais do gênero feminino nas cerâmicas contemporâneas e possivelmente nas peças arqueológicas no Amazonas - Brasil

the fauna and were in agreement with the gender that would use the containers, in the case of the alguidares. Finally, it came to the conclusion that the potters practiced a technique of millenarian ceramic modeling whose digital is still present in the contemporary containers and possibly in the past life.

Keywords: Contemporary ceramics; archaeological ceramics; material and immaterial culture; ceramics in the Amazon.

\section{INTRODUÇÃO}

O presente artigo tem o propósito de discorrer sobre a história das populações contemporâneas e pré-coloniais, sob a ótica dos contextos cerâmicos. Por sinal, gêneros humanos, em princípio, teriam certa divisão no âmbito dos espaços de reprodução social e, ao mesmo tempo, na confecção de utensílios em atividades familiares, a exemplo das diversas funções da mulher; uma delas é a de ser oleira (LÉVI-STRAUSS, 2010, p. 31). No Amazonas, pela sua dimensão geográfica, as populações humanas contemporâneas e pretéritas utilizaram dos ecossistemas (AB'SABER, 2003, 2008) de várzeas e de terras firmes (FONSECA, 2011) para elaborarem utensílios importantes e necessários às reproduções sociais e culturais em ambiente complexo (LEFF, 2006). Os primeiros viajantes europeus que desceram e subiram o rio Amazonas deixaram significativas informações a respeito de como as populações interagiam com o meio ambiente (CARVAJAL, 1941; ACUÑA 1994). A etno-história também descreveu como as populações se socializavam com as águas e as florestas (DANIEL, 2004; PORRO 2016; FRITZ, 2006). Nos sítios arqueológicos no Amazonas pré-colombiano estão assentadas as cidades, as vilas, as comunidades etc. Os sítios constituíam possíveis cidades indígenas (NEVES, 2006, 1999). Como exemplo disso, em 1975, na fundação da cidade de Urucurituba, vários vasos cerâmicos foram perturbados pelos serviços de terraplanagem. Desse modo, a intenção do texto foi observar como as oleiras de Manaquiri-AM utilizaram a argila para a confecção de vasos cerâmicos utilitários. Para tal, o caminho que se alinhavou foi realizar visita à comunidade de Cai N'água e perceber como as oleiras produziam os vasos cerâmicos em que adicionavam cinzas de cascas de madeira para torná-los mais resistentes ao uso doméstico.

\section{METODOLOGIA}

Postulou-se observar e participar (GIL, 1994, p.59) do processo de confecção dos vasos cerâmicos. Dessa forma, dirigiu-se ao município de Manaquiri-AM. O rio 
Digitais do gênero feminino nas cerâmicas contemporâneas e possivelmente nas peças arqueológicas no Amazonas - Brasil

homônimo fica à margem direita do rio Solimões-Amazonas. A sede municipal está assentada no Lago do Jaraqui. Para chegar à cidade, há duas alternativas: a primeira é utilizar o serviço de balsa que faz a travessia do Porto do CEASA - zona leste de Manaus - ao Careiro da Várzea; desse ponto, caminhar pela BR-319 até o km 101, acessar a BR252 e percorrer $42 \mathrm{~km}$ até a cidade; a segunda é o acesso do serviço de transporte fluvial, cujas lanchas saem todos os dias (manhã e tarde) do terminal da Feira da Manaus Moderna. Do porto da cidade, utiliza-se a canoa equipada com motor de popa ou rabeta; depois de uma hora de viagem, desembarca-se na comunidade de Cai N'água, onde as oleiras produzem os vasos cerâmicos.

Na figura 1, a localização do município, encaixado numa exuberante paisagem diversificada de espécies de palmeiras que foram e são resultantes de ações antrópicas produzidas por populações pré-colombianas e contemporâneas.

Figura 1: Mapa do Estado do Amazonas

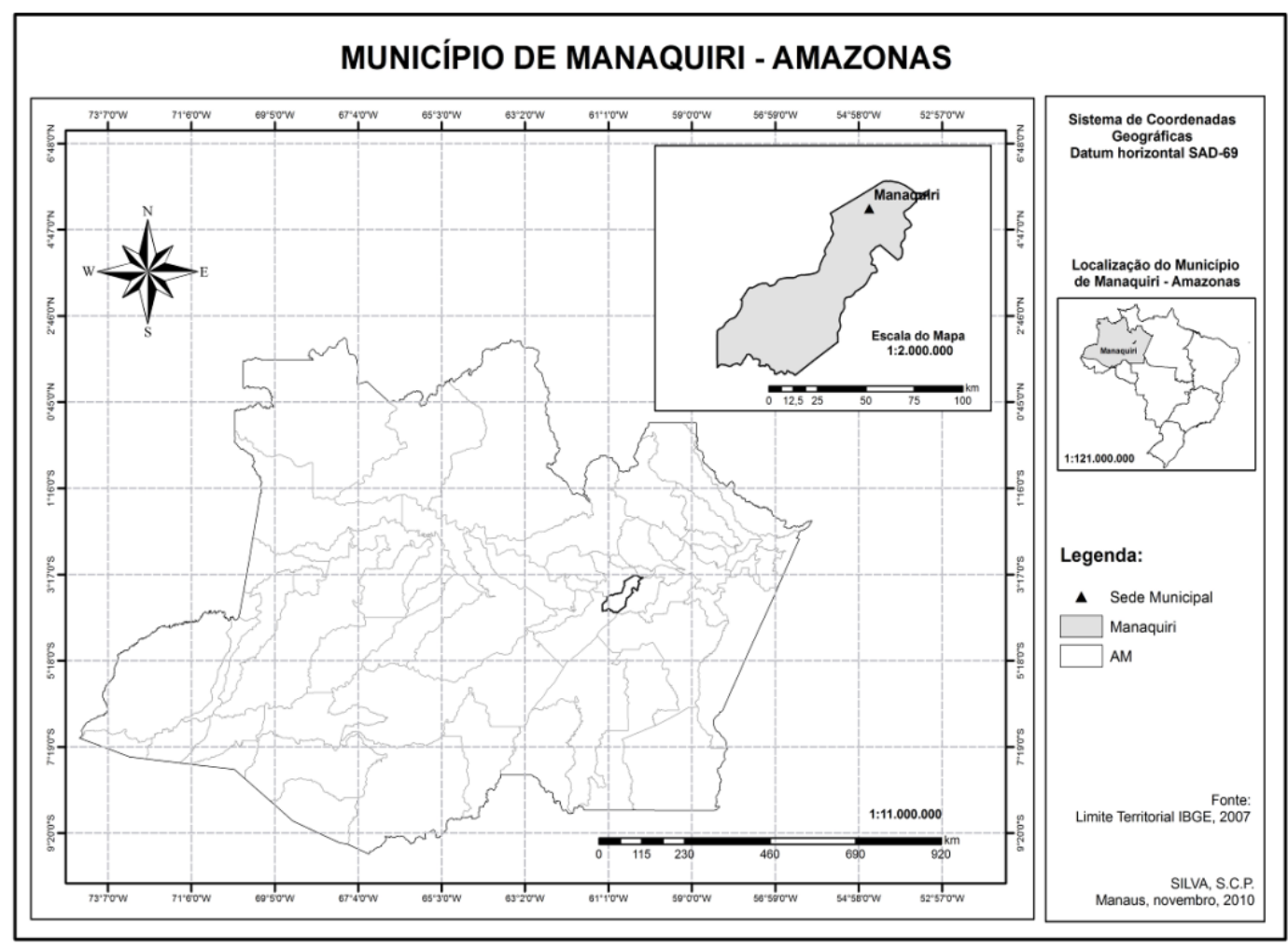

Fonte: SILVA, SCP, 2010.

A técnica de coleta de informações consistiu em acompanhar as oleiras no manuseio da argila para a confecção dos vasos cerâmicos. Elas já tinham um estoque desse material em processo, cujo armazenamento ocorria em uma pequena casinha, no 
Digitais do gênero feminino nas cerâmicas contemporâneas e possivelmente nas peças arqueológicas no Amazonas - Brasil

fundo das residências das oleiras. Essas mulheres retiravam as pelotas de argila de aproximadamente três a cinco quilogramas para a produção dos vasos. Os utensílios utilizados para manipular a argila, ou seja, as ferramentas de manuseio eram fragmentos de madeiras, de sementes e de pequenos seixos para processar o polimento aos vasos.

$\mathrm{Na}$ figura 2, estão os utensílios utilizados durante o manuseio das oleiras na confecção de vasos no sentido de dar à argila certa viscosidade e manter a durabilidade dos recipientes. Para tanto, as oleiras utilizavam as cascas de árvores, das quais se incluía o caraipé (Licania Utilis), espécie típica de ambiente de várzea baixa (FONSECA, 2011).

Figura 2: Imagens de utensílios para a confecção de vasos cerâmicos das oleiras de Manaquiri.

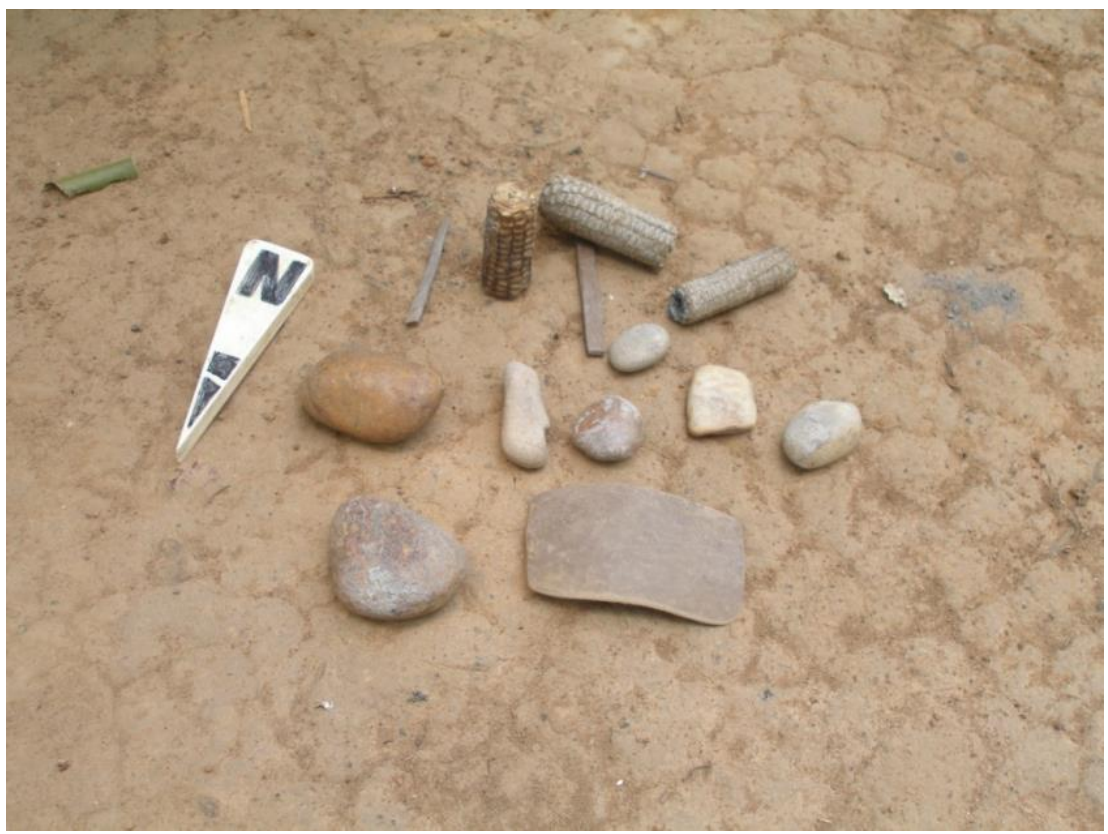

Foto: Carlos Augusto da Silva, 2010.

Também foi realizado levantamento de pesquisas arqueológicas na Amazônia que versam em relação à cerâmica pré-colombiana, entre as quais estão os trabalhos de (LIMA, 2008; GOMES 2002), que demonstram que as técnicas de produção de vasos cerâmicos consistiam em calibrar a argila, à qual adicionavam resíduos orgânicos e minerais para deixar a cerâmica com certa rigidez e manter a durabilidade dos vasos para a atividade do cotidiano.

\section{RESULTADOS E DISCUSSÃO}


Digitais do gênero feminino nas cerâmicas contemporâneas e possivelmente nas peças arqueológicas no Amazonas - Brasil

Em 1970, as ideias de Meggers \& Evans foram refutadas por Donald Lathrap na obra "El Alto Amazonas", que postulava que as regiões da Amazônia Central seriam um grande centro de domesticação de espécies de plantas e de cerâmicas. Consoante à teoria de Donald Lathrap, o arqueológico Eduardo Góes Neves, em 1995, inaugurou o terceiro momento da realização de pesquisas arqueológicas na Amazônia, cujos objetivos eram: 1) identificar grandes assentamentos às margens dos principais rios da região, lagos, igarapés, ilhas e furos; 2) verificar se os sítios arqueológicos na região foram densamente ocupados; 3) contribuir para a educação patrimonial na área da Amazônia Central (NEVES, 1999).

O adensamento da população pré-colombiana, de certa forma, está sendo confirmado, pois os sítios na região estão distribuídos por toda a área de terra firme e de várzea; e eles foram densamente ocupados, principalmente os que estão às margens dos principais rios da região, além dos de áreas de interflúvios, o que demonstra claramente que foram ambientes culturais. E, durante as etapas de campo em alguns municípios do Estado do Amazonas, observou-se que, em relação à cerâmica arqueológica identificada nos ecossistemas de terra firme ou de várzea, em alguns deles possivelmente havia as digitais do gênero feminino, ou seja, das oleiras.

No Estado do Amazonas, os sítios arqueológicos, que chegam entre $1 \mathrm{~m}$ e 1,5m de profundidade, estão nos ambientes de terra firme e de várzea, os quais geralmente estão em ambiente de terra preta de índio e são cobiçados pelos agricultores para cultivar mamão (NEVES, 2006, p. 54). Nesses sítios, dependendo do processo de atividade agrícola, os vestígios estão em superfície; com frequência, são encontrados muitos fragmentos cerâmicos, líticos e, às vezes, restos de fauna e de ossada humana. Já nos sítios em área de várzea, os estratos de ocupações são menos profundos: chegam entre $70 \mathrm{~cm}$ e $100 \mathrm{~cm}$. Todavia, pelo fato de o pasto do gado fazer uma espécie de forragem, formada pelo entrelaçado das raízes do capim, isso dificulta a visibilidade de percepção de vestígios em superfície.

E, assim, nos dois ecossistemas de terra firme e de várzea, ocorreram intensas modificações em práticas agrícolas que remontam a milhares de anos na região. E também a arte de elaborar vasos cerâmicos são as marcas e as evidências de que o gênero feminino esteja representado e afixando sua identidade por meio da confecção de vasos cerâmicos utilitários ou simbólicos. Assim, tanto no registro arqueológico, quanto no contemporâneo, existe o design de ações que podem identificar a presença do intelecto 
Digitais do gênero feminino nas cerâmicas contemporâneas e possivelmente nas peças arqueológicas no Amazonas - Brasil

arquitetônico na cerâmica, que são as assinaturas, por meio de digitais, em vasos cerâmicos. A figura 3 é um recipiente encontrado em contexto arqueológico.

Figura 3: Vaso policromo sendo escavado pelas águas pluviais.

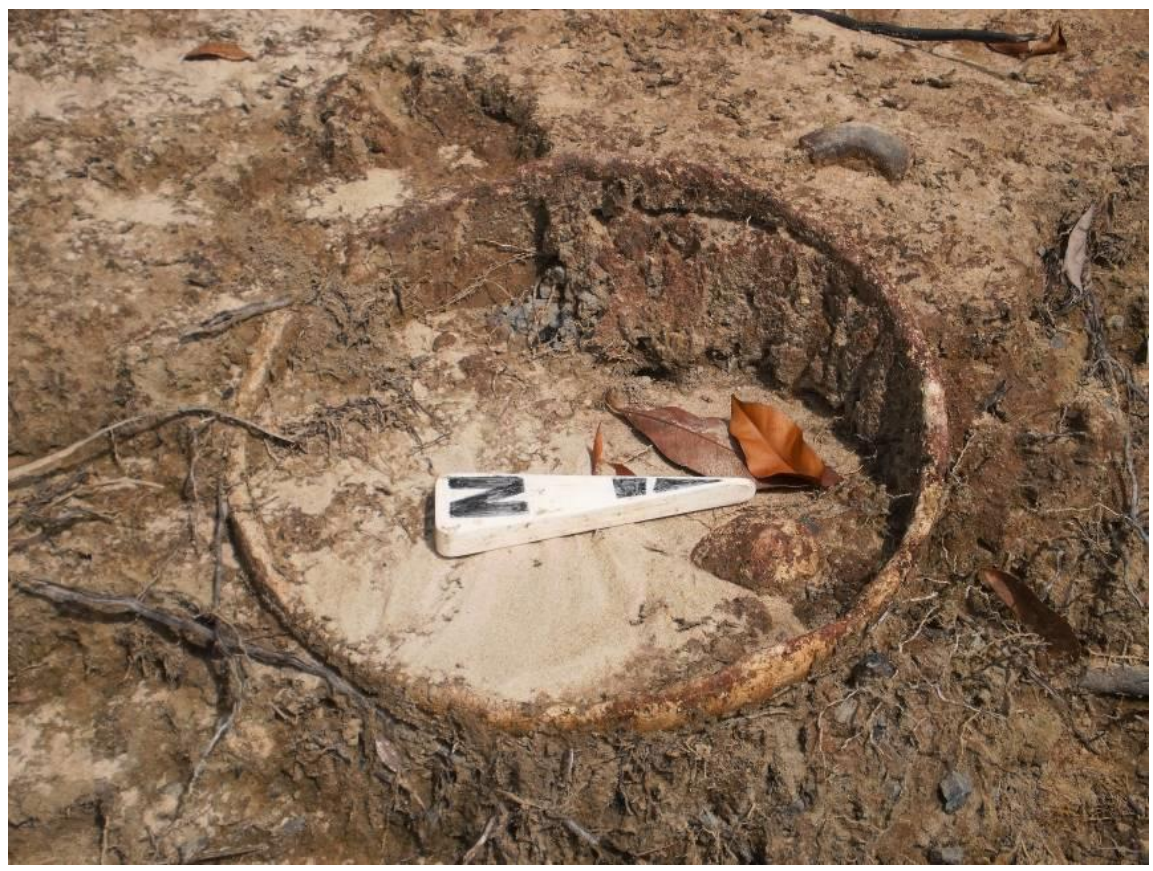

Foto: Carlos Augusto da Silva, jul. 2012.

No Amazonas, principalmente nas cidades que estão próximas à margem dos rios, devido ao processo de urbanização, ocorrem as intervenções no solo por meio de terraplanagem. Essas intervenções abrem perfis, os quais expõem fragmentos cerâmicos, que, por sua vez, revelam o modelo de vida das populações amazônicas précolombianas. E, assim, os fragmentos expostos denotam as características que aparecem nos vasos cerâmicos de Manaquiri. Logo se pode inferir que as oleiras dos dois segmentos (arqueológico-contemporâneas) utilizaram saberes das práxis do cotidiano para a confecção de vasos cerâmicos em níveis utilitários e simbólicos (LÉVISTRAUSS, 2010).

Geralmente, nos sítios arqueológicos, são encontrados fragmentos cerâmicos de vasilhas para as quais poderia haver distintas funções, tais como o torrador, os potes, o alguidar, vasos de diversos tamanhos etc. Esses modelos ainda são confeccionados e utilizados no dia a dia de algumas oleiras da Região Amazônica e sugerem que a arquitetura dos recipientes tem similaridades em relação aos saberes milenares de populações ameríndias pré-coloniais.

O torrador é um recipiente confeccionado de argila, geralmente de tamanho 
Digitais do gênero feminino nas cerâmicas contemporâneas e possivelmente nas peças arqueológicas no Amazonas - Brasil

médio, utilizado para cozer diversos alimentos, uma delas de assar o beiju. Seu estilo é rústico no sentido de suportar a temperatura de aproximadamente 100 graus, cujo tempero é o caraipé ou hematita, que é uma árvore comum em áreas de igapós, dos ecossistemas de terra firme e de várzea. As oleiras retiravam as cascas do caraipé; em certas porções, deixavam-nas ao sol por vários dias; e, após esse tempo, depois de as cascas estarem bem secas, queimavam-nas. Em seguida à queima, entre três ou quatro dias, reuniam as cinzas e levavam-nas ao pilão (objeto confeccionado de madeira, com orifício ao centro, com a abertura de $20 \mathrm{~cm}$ de largura, de $30 \mathrm{~cm}$ ou $40 \mathrm{~cm}$ extensão, no sentido vertical). Geralmente, o pilão é confeccionado de madeira resistente no sentido de não ceder ao impacto das batidas; durante o processo de trituração das cascas do caraipé (Licania Utilis), elas já foram transformadas em cinzas, então era adicionada a argila para gerar uma mistura viscosa. Em Manaquiri, em todas as cerâmicas, os temperos são de cascas de árvores, das quais a mais utilizada é o caraipé, porém há outras cascas de árvores que são usadas, como é caso do muruxi (Byrsonima Crassifolia). A figura 4 traz uma paisagem com exemplares de caraipezeiro, típico do igapó de área de várzea.

Figura 4: Árvores de caraipé e de muruxi utilizadas no tempero da argila para a confecção de cerâmica em Manaquiri. Paisagem de igapó com diversos exemplares de carapeizeiros; as setas indicam diversos exemplares das espécies supracitadas.

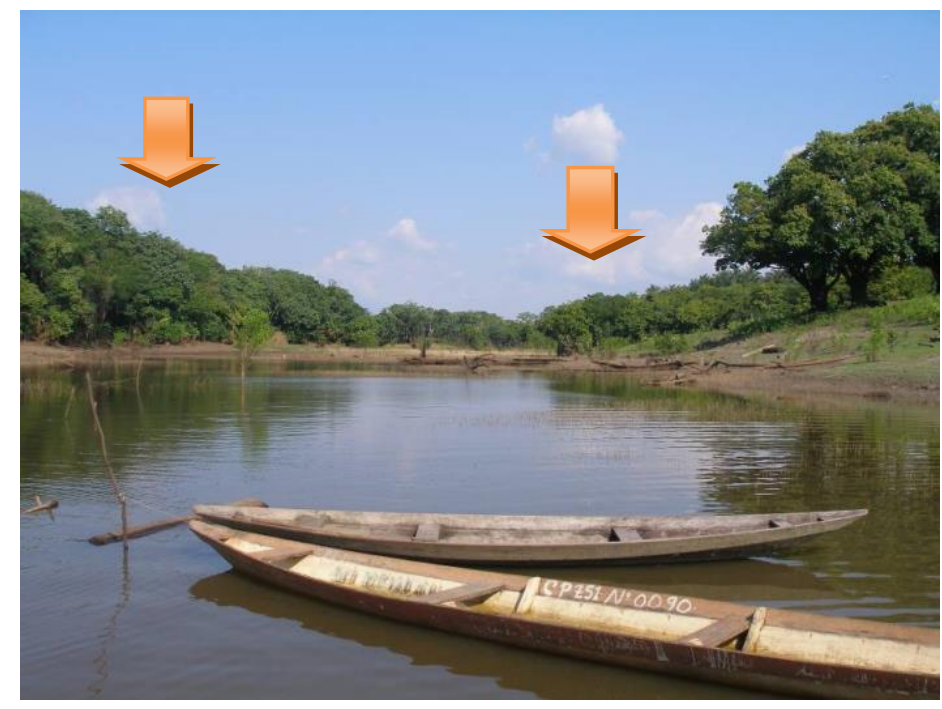

Foto: Carlos Augusto da Silva, jul. 2010.

Depois de as cinzas estarem trituradas, como se fossem farinha de macaxeira, depositavam-nas nos recipientes de madeira chamados gamelas (são os troncos de árvores ocas; ao serem divididas ao meio, formam uma espécie de canoa), ou também nas sobras 
Digitais do gênero feminino nas cerâmicas contemporâneas e possivelmente nas peças arqueológicas no Amazonas - Brasil

de cachos de bacabas (Oenocarpus bacaba) ou de inajás (Attalea maripa), que, depois de algum tempo, se desprendem das árvores e formam uma pequena canoa.

No entanto o pilão de madeira não resistiu às intempéries da região. Por essa razão, não foi identificado nos registros arqueológicos. As informações de confecções de recipientes foram obtidas a partir de duas antigas oleiras do lago do Mirauá e do igarapé do Cai N’água, em Manaquiri, no Amazonas. As oleiras são de uma tradição de famílias de ceramistas, que remontam a uma história de mais de meio século (SILVA, 2010, p.86), em modelagens de objetos cerâmicos utilitários e simbólicos.

O pote geralmente é um recipiente que foi utilizado de forma ampla pelas populações humanas na Amazônica pré-colonial. Os registros arqueológicos demonstram que os potes tinham, possivelmente, as funções de armazenamento de água potável, depósito de diversas espécies de sementes, de bebidas, ou para sepultamento humano, ou seja, eram recipientes que serviam por longo tempo a determinados grupos humanos.

A cerâmica utilitária consiste em recipientes confeccionados para o uso cotidiano de populações da Amazônia pré-colombiana. Esses artefatos possivelmente eram produzidos no sentido de atender à necessidade do cotidiano de determinado grupo social. Os sítios arqueológicos representam, pois, os locais que foram modificados pelas populações que habitaram as margens dos rios e dos interflúvios (NEVES, 2006). Esses locais de comunidades longínquas são chamados de roçados do centro pelas populações que residem nas várzeas (são as pessoas que habitam as margens dos rios, lagos, ilhas, igarapés etc.), as quais modificam as paisagens por meio da introdução de espécies nativas, que lhes servem na dieta alimentar, como açaí (Euterpe oleracea), bacaba (Oenocarpus), uxi (Endopleura uchi), umari (Poraqueiba sericea Tulasne), castanha (Bertholletia excelsa), castanha-sapucaia (Lecythis pisonis) e outras (SILVA, 2010, p. 34).

No processo de confecção do pote, era utilizada a argila especial, e os temperos eram de caraipé e de cauixi. A argila especial era retirada de áreas próximas aos leitos dos rios, lagos ou igarapés de várzeas. Segundo informação das oleiras de ManaquiriAM, são:

\footnotetext{
Áreas próximas das beiras dos rios ou dos lagos; quando estes estão secando, os barreiros começam a sair; é nesse momento que, depois de ser observada, a mãe lhes permite sair. Escolhemos os locais para que, entre os meses de outubro e dias de novembro, quando o barro está maduro, e com a subida das águas, a canoa encoste próximo do barreiro. Então, fazemos recomendações à mãe natureza para que as louças não quebrem quando estiverem sendo queimadas. Retiramos as bolotas, embarcamos na canoa e
} 
Digitais do gênero feminino nas cerâmicas contemporâneas e possivelmente nas peças arqueológicas no Amazonas - Brasil

depositamos debaixo do assoalho da casa para que, no ano seguinte, sejam feitas as louças. (Comunicação pessoal - Senhores Manuel, 72 anos; e Raimunda, 79 - setembro 2010).

Tudo indica que a voz do gênero feminino contemporâneo representa traços de uma linha no tempo, pois há toda uma formalidade para a aquisição do recolhimento da matéria-prima (a argila e as cascas de árvores) para a confecção de recipientes cerâmicos pelas oleiras da comunidade Cai N'água de Manaquiri-AM.

O pote geralmente é um recipiente de tamanho médio ou grande; e há toda uma preparação no seu processo de confecção. Conforme se observou na confecção desses recipientes, as oleiras empregavam uma técnica de modelagem de longo tempo, pois, ao iniciar a base do artefato, utilizavam folhas de imbaúba ou de sororoca. Porém, antes disso, faziam no solo uma estrutura plana para começar a erguer a base do recipiente. Então a argila já previamente preparada ficava com aparência de massa de bolo. Assim, retiravam uma porção e, sobre uma peça de madeira, começavam a fazer os cordões (roletes) para que, na sequência, os distribuíssem em volta da base do pote, depois de várias vezes utilizando água e carapaça do uruá para moldar e para proceder a alguns nivelamentos na parede do pote. E, ao cair da tarde, o recipiente já apresentava uma forma de um vasilhame de média dimensão.

Após quatro ou cinco dias, começava a parte final do pote, que era a colocação do "pescoço", ou seja, do gargalo e das alças que ficam na parede externa. Parece-nos que há uma conotação bastante implícita de presença de outro ser, que tem vida, na confecção de potes cerâmicos, ou seja, a designação pescoço parece soar como uma vida humana, no sentido de dar mais estética ao pote - a última etapa antes de o pote ser queimado. As oleiras faziam os retoques no recipiente, em volta do gargalo; no bojo, colocavam uma linha circundando o pote; na sequência, acrescentavam uma corda de argila em volta dele. É nesse processo que se fixavam nitidamente as digitais da oleira no recipiente de argila, pois no cordão friccionavam com o dedo polegar ou o indicador, deixando a marca da oleira. Na figura 5, pode-se perceber uma intenção de sustentar o recipiente para que, com o processo de retoque ou de acabamento, ele não se rompesse, ou seja, não quebrasse. 
Figura 5: Vaso cerâmico, denominado pelas oleiras de "janelão ou boião", com o cordão ou rolete envolto, com a função de estabilizar a borda e as incisões das digitais da oleira.

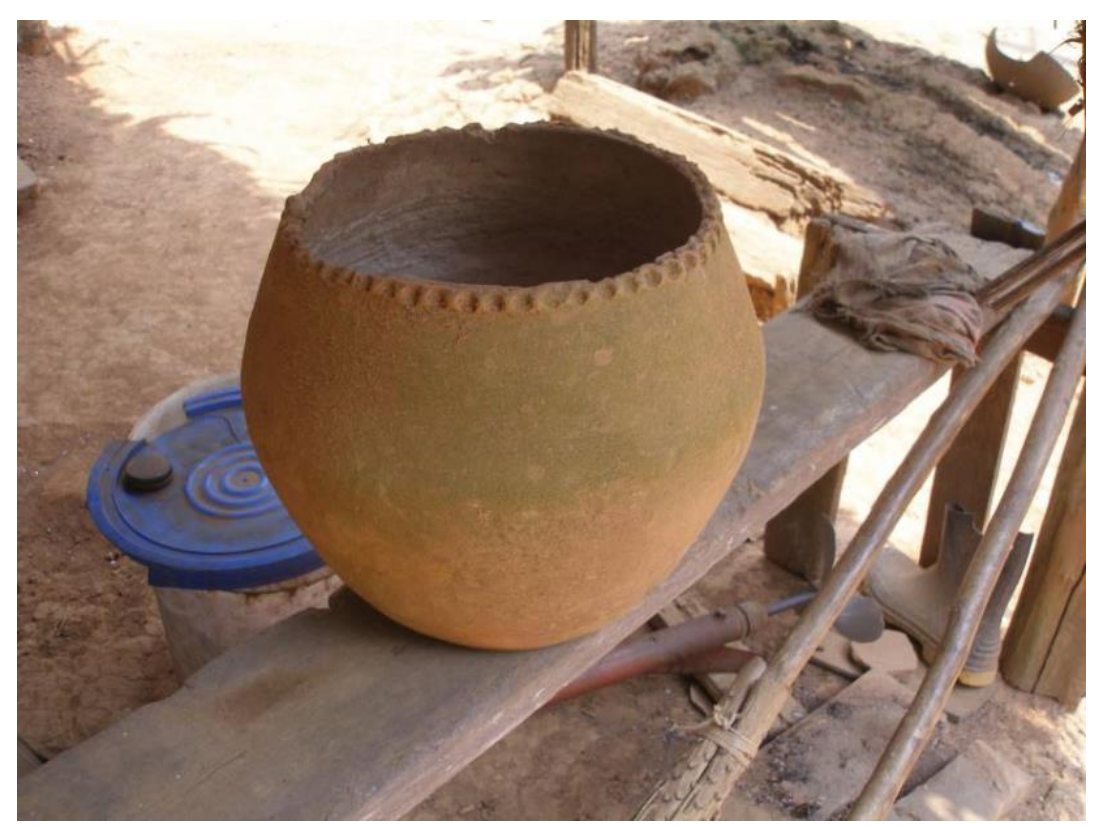

Foto: Carlos Augusto da Silva, set. 2010.

Há várias formas de colocar e de retirar o pote do "banho de sol" - é o termo socializado pelas oleiras, pois, durante as primeiras horas da manhã e no fim de tarde, o pote é levado ao sol para que a argila fique resistente e receba cor. Segundo as oleiras, é o banho de sol que vai determinar se o recipiente vai queimar bem, ou seja, se o recipiente não quebrará durante o processo de cozimento ao fogo.

Entre 30 (trinta) e 45 (quarenta e cinco) dias, o pote estará seco, já terá cor, então chegará o dia de fazer a queima ou o cozimento. As oleiras vão ao roçado e coletam três ou cinco feixes de lenha, a qual tem de ser obtida de árvores bem secas, resistentes, ou seja, que demorem a queimar. Geralmente, o processo de queima do pote é realizado em áreas afastadas das residências. Segundo as oleiras, é uma espécie de crendice em ciúmes, pois, se as pessoas chegarem ao recinto, e não fizerem parte do círculo de amizade delas, o pote poderá sofrer avarias durante o processo de queima. Assim, esse procedimento ocorre distante das residências; trata-se, pois, de uma espécie de prevenção cultural e de saberes ancestrais.

Assim, no local, é feita uma área plana no solo para que o pote fique fixo, então é colocada a lenha em volta do recipiente até uma altura de $80 \mathrm{~cm}$ a $100 \mathrm{~cm}$. A lenha tem de ficar em posição horizontal até cobrir totalmente o pote. Na sequência, ela é colocada no sentido vertical, de forma que os filetes fiquem bem unidos para que não haja aberturas. Após esse procedimento, as oleiras picotam a lenha em fragmentos bem 
Digitais do gênero feminino nas cerâmicas contemporâneas e possivelmente nas peças arqueológicas no Amazonas - Brasil

pequenos, que elas chamam de "cavaco"; este é colocado em quatro posições em forma de círculo, debaixo das lascas de lenha. Na sequência, é ateado fogo nos cavacos. E as labaredas começam a aumentar; depois de 1 (uma) ou 2 (duas) horas, a lenha já virou carvão, e o pote começa a esfriar. Então, tem início a parte final do processo, que é a impermeabilização do pote.

A impermeabilização é realizada assim: as oleiras retiram o pote do meio dos carvões da fogueira e colocam-no numa posição segura; começam o processo de friccionar uma matéria-prima, a que elas chamam de "jutaícica", por todo o pote. Após esse processo, o artefato fica brilhoso e cheiroso. E, depois de alguns dias, é colocada água no pote, que fica cheio por cinco ou seis dias em local arejado, ou seja, está sendo preparado para o uso. Após três ou cinco dias, o pote é enxaguado com água limpa. E voltam a colocar água nele para testar se o pote realmente está impermeável e se o cheiro do jutaícica (Hymenea courbaril L.) desapareceu. Se confirmado, o pote está efetivamente preparado para ser utilizado no cotidiano das pessoas. O pote para atividade do dia a dia é utilizado como depósito de água potável e fica geralmente na parte da cozinha, ou na casinha que fica próximo ao jirau - é o local onde são tratados os peixes e em que é feita a limpeza das vasilhas das residências. Geralmente, a água do pote que fica nessas duas partes ou compartimentos da casa não pode ser utilizada para ser aquecida, senão, conforme as oleiras, os potes não mais esfriarão águas. Destarte, nos dias muito quentes, a água ficaria morna e, assim, não seria apropriada para consumo, ou seja, para a ingestão no sentido de saciar a sede.

O pote também seria utilizado como utensílio social, e o processo de confecção era feito por meio de encomenda para atender às famílias de outras comunidades cujo gênero feminino não possuía a habilidade para a produção de vasos cerâmicos; nesse sentido, as oleiras recebiam em troca outros produtos por elas não produzidos - no caso os traçados como peneiras, paneiros, abanos etc. As oleiras tinham uma espécie de planta ou desenho, pois passavam aos solicitantes uma caracterização estética do pote. Esse protótipo poderia ser de tamanhos grandes ou pequenos. Os grandes eram utilizados para depositar semente ou farinha; os pequenos, geralmente, tinham a função de acondicionar os utensílios das lideranças que zelam pela saúde das pessoas (crianças, mulheres gestantes, idosos).

Então como produzir potes que atendam à necessidade do usuário? Uma possível resposta é a experiência das oleiras, as quais utilizavam menos ou mais matéria-prima na confecção desses recipientes. Um exemplo é o pote de gargalo grande, que era 
Digitais do gênero feminino nas cerâmicas contemporâneas e possivelmente nas peças arqueológicas no Amazonas - Brasil

utilizado na coleta de goma. Esta vem adicionada ao tucupi; se o pote não fosse confeccionado para esse fim, poderia acarretar dificuldade de uso, pois o tucupi, devido ao excesso de acidez, poderia pouco a pouco fragmentar-se em sua parte interna. $\mathrm{Na}$ figura 4, um pote de gargalo grande que, segundo a oleira, "pode ser utilizado em várias atividades; uma delas é para acondicionar leite bovino, pois o pote de barro possibilita o gosto delicioso da coalhada" (Comunicação pessoal de Dona Raimunda, 79 anos, oleira de Manaquiri-AM, setembro de 2010).

Figura 6: Pote utilizado para acondicionar a água potável para o uso da oleira, impermeabilizado por jutaícica (Hymenea courbaril L).

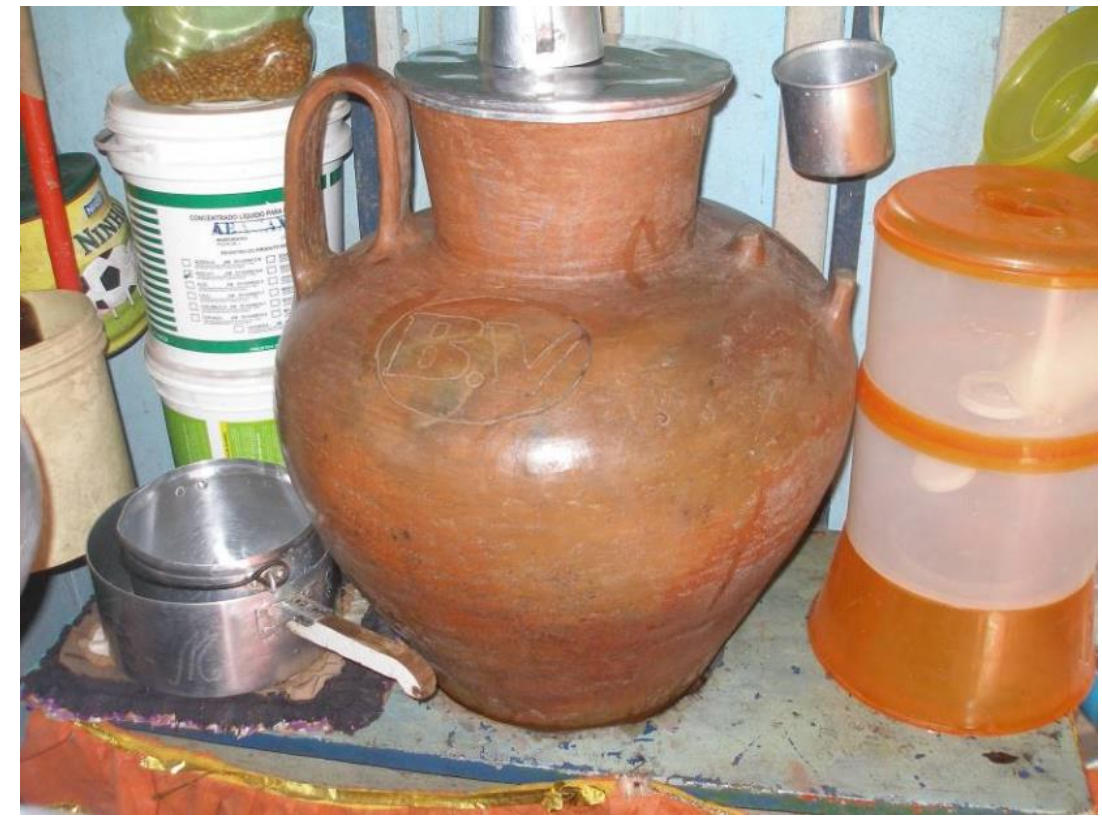

Foto: Carlos Augusto da Silva, set. 2010.

Como se vê na figura 4 , o pote tem em seu bojo a assinatura da oleira, tracejada por pequenos orifícios do alfabeto da Língua Portuguesa, mediante a fricção em torno da circunferência do recipiente. A essa característica (LEFF, 2006, p. 415), chamamos de "modo de viver no meio rural"; trata-se de lidar com a lógica da descoberta, pois a criatividade de confeccionar recipiente de argila está presente no mapa mental das oleiras de Manaquiri-AM; o alguidar é um molde que está em sua memória, logo pode ser classificado como patrimônio imaterial. É um recipiente confeccionado de vários tamanhos, com a função de atender à necessidade das pessoas. Uma necessidade que foi informada pelas oleiras é a de que, antes dos anos de 1960, as famílias, geralmente, solicitavam às oleiras alguidares, cuja função era a de servir de banheira para o bebê. 
Digitais do gênero feminino nas cerâmicas contemporâneas e possivelmente nas peças arqueológicas no Amazonas - Brasil

Assim, o alguidar teria de ter estética; de modo geral, era bem elaborado, com desenho fundamentado em características de animais da fauna, segundo as oleiras, para "o curumim ou a cunhatã". Se o alguidar tivesse representação de animal robusto ou encantado, como onças, antas, porcos-do-mato, macacos, seriam reproduzidas figuras antropomórficas masculinas; já se o alguidar fosse para ser usado por bebê do sexo feminino, seria caracterizado por animais da fauna como araras, papagaios, curicas e outras espécies de animais de cantos harmônicos.

Afora essas funções, o alguidar também era utilizado para acondicionar diversos produtos da culinária da Amazônia. A exemplo disso, nas altas temporadas das secas dos rios da região, há as piracemas; e, à medida que as águas vão descendo, vão surgindo as praias. Nestas, eram realizados verdadeiros banquetes, nos quais eram montados grandes moquéns para a prática de assar peixes de todas as espécies, para fazer a farinha de peixe natural ou orgânico, ou seja, o delicioso piracuí - e o alguidar era empregado para esses fins.

No processo de feitura do piracuí, é retirada a ossada dos peixes; geralmente, os que ficam em áreas de lagos da região são bodós, curimatãs, aruanãs, caparari, tucunaré; então, os peixes são assados, descarnados. Na sequência, a massa de peixe é colocada em alguidares para ser levada ao fogo. Após uma ou duas horas do processo de torrefação, o piracuí está pronto para o consumo humano, por um período de seis meses ou mais. Eis a farinha de peixe, cujos ingredientes culinários estão na "memória das populações dos rios do Amazonas" (SILVA, 2010, p.53). As figuras 7 e 8 demonstram a parte interna e a externa de um alguidar; na parte polida, é possível observar o polimento feito com jutaícica; e, na parte externa, na borda e no bojo, está o processo de digitalização do polegar da oleira.

Figuras 7: Alguidar confeccionado para o uso doméstico da oleira.

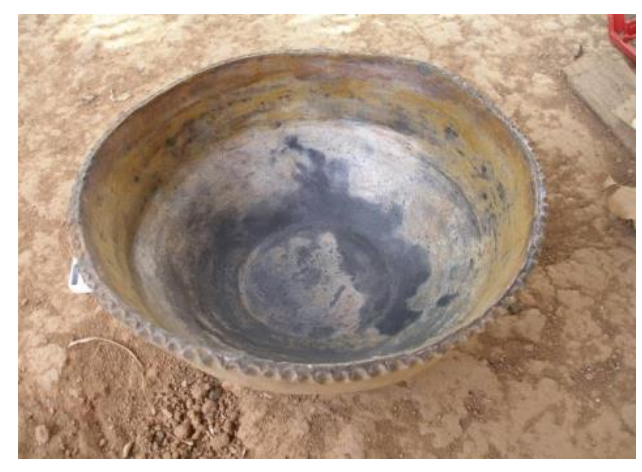

Foto: Carlos Augusto da Silva, 2010. 

arqueológicas no Amazonas - Brasil

Figura 8: Imagem de alguidar: O design do alguidar e os cordões de argila circundando o recipiente onde há as digitais da oleira.

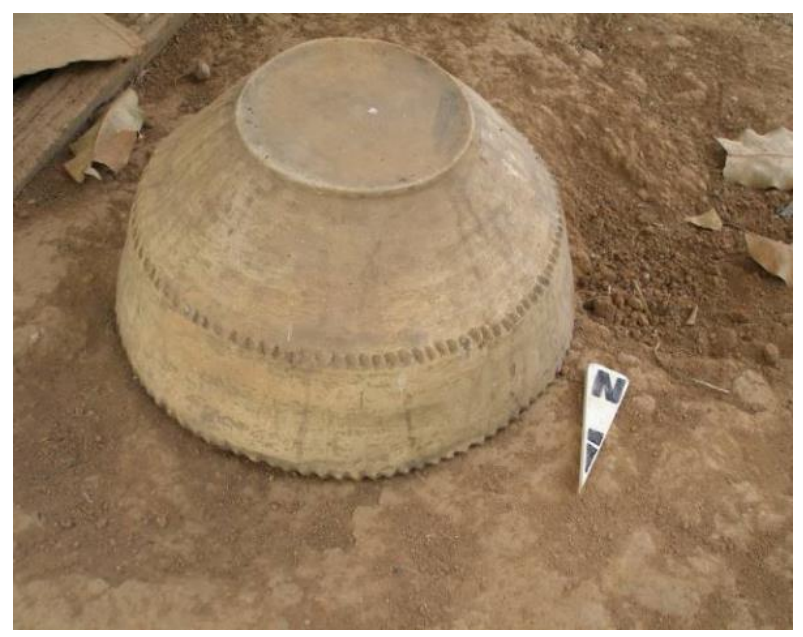

Foto: Carlos Augusto da Silva, 2010

\section{CONSIDERAÇÕES FINAIS}

O artigo caminhou pelo labirinto de dados disponíveis na literatura arqueológica e histórica e por meio de experiências dos autores ao realizarem pesquisas em ambientes de várzea e de terra firme ou ao acompanharem pesquisas arqueológicas nas conexões dos rios Negro e Solimões-Amazonas. A pesquisa apontou certos modelos de vida daquelas populações; e alguns deles ainda se fazem presentes, porém com certa timidez ante o avanço da cultura globalizada. As oleiras de Manaquiri-AM, município ao sul de Manaus, vêm conduzindo uma tradição ceramista em que a assinatura nos recipientes cerâmicos pode ter correlação com as oleiras da cultura ceramista Paredão, pois as técnicas utilizadas pelas oleiras de Manaquiri têm certa correlação com essa fase. Por exemplo, os potes confeccionados pelas oleiras de Manaquiri, os processos de polimento na parte externa do pote são similares aos potes da cultura ceramista Paredão (NEVES, 2006). Nos recipientes desta, geralmente, o alguidar em torno da borda é tracejado com pontinhos, em alto relevo. Possivelmente, esse pontilhado era produzido com a fricção do dedo polegar das oleiras.

As oleiras de Manaquiri, no Amazonas, nos recipientes como o pote, o pote bojudo, o alguidar e em outros artefatos menores, introduziam a sua assinatura digital, friccionando o dedo polegar sobre o rolete em volta do bojo ou da base deles. Esses mesmos acabamentos, como o polimento em todo o recipiente, eram aplicados tanto na parte interna quanto na externa e eram realizados em conformidade com a função do artefato, quer para uso doméstico, quer para utilização em rituais. 
Digitais do gênero feminino nas cerâmicas contemporâneas e possivelmente nas peças arqueológicas no Amazonas - Brasil

\section{REFERÊNCIAS}

AB'SABER, Aziz Nacib. Ecossistema do Brasil. Marigo. São Paulo: Metalivro, 2008.

AB'SABER, Aziz Nacib. Os domínios de natureza no Brasil: potencialidades paisagísticas. São Paulo: Ateliê Editora, 2003.

ACUNÑA, Cristóbal de. Sacerdote, 1597-1675. Novo descobrimento do grande rio das Amazonas. Tradução de Helena Ferreira; revisão de Moacyr Werneck de Castro; revisão de José Tedin Pinto. Rio de Janeiro: Agir, 1994.

CARVAJAL, Gaspar de. Descobrimento do Rio de Orellana. São Paulo/Rio de Janeiro: Companhia Editora Nacional, 1941. (trecho entre o rio Negro e o Tapajós).

DANIEL, Padre João. Tesouro descoberto no máximo Rio Amazonas. Volume 2, Rio de Janeiro: Contraponto, 2004.

FONSECA, Osorio J.M. Pensando a Amazônia. Manaus: Editora Valer, 2011.

FRITZ, Padre Samuel. O diário. (Org.) PINTO, Renan Freitas. Manaus: Editora da Universidade Federal do Amazonas e Faculdade Salesiana Dom Bosco, 2006.

GIL, Antônio Carlos. Métodos e técnicas de pesquisa social. Atlas, 1999.

LEFF, Enrique. Racionalidade ambiental: a reapropriação social da natureza. Rio de Janeiro: Civilização Brasileira, 2006.

GOMES, Denise Maria Cavalcante. Cerâmica arqueológica da Amazônia: vasilhas da coleção tapajônica MAE-USP. São Paulo: Editora da Universidade de São Paulo, 2002.

LÉVI-STRAUSS, Claude. A oleira ciumenta. Lisboa: Biblioteca Nacional de Portugal, Catalogação na Publicação. Paginação, Impressão e Acabamento: Pentaedro Ltda., abril, 2010 .

LIMA, Helena Pinto. História das caretas: a tradição borda incisa na Amazônia Central. 2008. 538ff. Tese (Doutorado em Arqueologia) - Museu de Arqueologia e Etnologia, Universidade de São Paulo, São Paulo.

NEVES, E.G. Duas interpretações para explicar a ocupação da Pré-história na Amazônia. In: Pré-história da Terra Brasilis. TENÓRIO, Maria Cristina (Org.). Rio de Janeiro: Editora UFRJ, 1999.

Arqueologia da Amazônia. Rio de Janeiro: Jorge Zahar Ed., 2006.

PORRO, Antônio. O povo das águas: ensaio de etno-história amazônica. Rio de Janeiro: Vozes, 2016. 
Digitais do gênero feminino nas cerâmicas contemporâneas e possivelmente nas peças arqueológicas no Amazonas - Brasil

SILVA, Carlos Augusto da. A dinâmica do uso da terra nos locais onde há sítios arqueológicos: o caso da comunidade Cai N'água, Manaquiri-AM. Manaus, 2010. 153ff. (Mestrado em Ciências do Ambiente e Sustentabilidade na Amazônia) - Centro de Ciências do Ambiente, Universidade Federal do Amazonas. 